\title{
A inclusão do profissional enfermeiro em instituições que oferecem educação infantil
}

\author{
The inclusion of the nurse professional in institutions \\ that offer child education
}

\author{
Camila Utz Pessota ${ }^{1}$ \\ Marlis Polidori ${ }^{1}$ \\ Caroline Dani ${ }^{1}$
}

\section{RESUMO}

A atuação do profissional enfermeiro no ambiente escolar é muito importante para acompanhar de forma segura o desenvolvimento e crescimento da criança. O artigo teve como objetivo Conhecer a percepção dos enfermeiros, professores e supervisores pedagógicos quanto a inclusão do profissional enfermeiro em duas instituições de educação infantil municipais e duas particulares em Porto Alegre. Trata-se de estudo qualitativo, exploratório de cunho descritivo, realizado com 4 supervisores pedagógicos (1 por escola), 4 enfermeiros (1 por escola) e 20 professores (5 por escola) de educação infantil de Porto Alegre. A entrevista foi aplicada após a aprovação do Comitê de Ética do IPA e da Secretaria de Educação do Município de Porto Alegre e os dados foram submetidos ao método de análise temática. Os resultados mostraram a importância do profissional enfermeiro em atuar de maneira efetiva nas escolas de educação infantil promovendo e estimulando atividades educativas e assistenciais neste ambiente uma vez que seu curso de formação os confere estar apto tendo conhecimento sobre o crescimento e desenvolvimento da criança em idade escolar. A escola é um ambiente favorável para o desenvolvimento de práticas relacionadas à saúde conclui-se que a inclusão do enfermeiro nas instituições escolares torna-se necessária uma vez que junto com a equipe multiprofissional e apoio dos pais possam desenvolver práticas educativas promovendo a saúde e contribuindo para evitar doenças e acidentes escolares. A partir do estudo desenvolvido se espera contribuir para o melhor conhecimento do tema por parte das escolas e dos governantes, reforçando a presença do enfermeiro

\author{
Palavras-chave \\ Enfermagem. Enfermeiro nas escolas. Educação infantil.
}

\footnotetext{
${ }^{1}$ Programa de Pós-Graduação Acadêmico em Biociências e Reabilitação (PPGBR), do Centro Universitário Metodista - IPA; Porto Alegre-RS, Brasil. nas escolas entre elas as de educação infantil proporcionando um atendimento com melhor qualidade aos pais, colaboradores e crianças do serviço, gerando um sentimento de tranquilidade e segurança aos pais que procuram o serviço.
} 


\section{ABSTRACT}

The role of the professional nurse on the school environment is very important to observe safely the children's development and growth. The article aimed to understand the perception of nurses, professors and supervisors about the inclusion of the nurse in two municipal and private institutions of childhood education in Porto Alegre. It is a qualitative and explorative analysis of a descriptive nature, developed with 4 pedagogical supervisors ( 1 per school), 4 nurses ( 1 per school) and 20 professors ( 5 per school) of childhood education in Porto Alegre. The interview was applied after The Ethics Committee of IPA and the Department of Education of the City of Porto Alegre's approval and the collected data were submitted to the thematic analysis method. The results showed how important is the nurse's effective performance on the childhood education schools, promoting and stimulating educational and welfare activities in this environment once their graduation course gives them the knowledge about the child's development and growth under school age. The school being a favorable environment for the development of health-related practices it's concluded that the inclusion of the nurse in scholar institutions is necessary once that together with a multiprofessional staff and the parent's support can develop educational practices promoting health and contributing to prevent diseases and school accidents. The study is expected to contribute to a better knowledge of the matter by schools and governments, strengthen the presence of nurses in schools, including childhood education providing a better quality service to parents, contributors and children, generating a feeling of tranquility and security for parents seeking the service.

\section{KEYWORDS}

Nursing. Nurse in schools. Childhood education. 


\section{INTRODUÇÃO}

A enfermagem é uma profissão da área da saúde, a qual tem como essência o cuidado ao ser humano, individual, na família ou na comunidade (SALAZAR, 2011). Nessa perspectiva a inserção do profissional enfermeiro nas escolas que oferecem educação infantil torna-se importante uma vez que junto à equipe multiprofissional possam prestar uma assistência individualizada ao aluno e suas famílias. Essa assistência tem por finalidade a prevenção e cuidados com a saúde nessa faixa etária possibilitando um adequado e tranquilo desenvolvimento neuro psico motor.

As novas alterações na Lei de Diretrizes e Bases foram estabelecidas pela Lei 12.796 no dia 4 de Abril de 2013 a qual torna obrigatória a matricula realizada pelos pais, e ou responsáveis na educação básica a partir dos 4 anos de idade. $O$ atendimento à criança deve contemplar no mínimo quatro horas diárias para o turno parcial e sete para a jornada integral o mesmo modelo já existente no ensino fundamental e médio.

Nos estabelecimentos educacionais ocorre o contato mais próximo do profissional enfermeiro, professores e supervisor com a criança e sua família possibilitando assim o conhecimento das condições de vida e saúde da população atendida no serviço e a troca e socialização das informações. Segundo Saraiva et al. (2007), cada individuo da família possui a sua própria singularidade, com seus próprios valores e opiniões, ou seja, cada família tem seu estilo de vida, e demonstra seus sentimentos de forma diferente. Quando um dos membros da família encontra-se doente, os outros também, de certa forma, "adoecem" (MORAES; COSTA, 2009).

A realização da consulta de enfermagem no ambiente escolar permite realizar o acompanhamento do crescimento e desenvolvimento da criança e estabelecer condutas preventivas junto com o apoio e integração dos pais, para que em casa se garanta a continuidade do trabalho realizado. A Consulta de enfermagem deve ser realizada individualmente levando em consideração a faixa etária da criança e suas especificidades. O curso de formação do profissional enfermeiro the confere qualificação para tal atuação (COFEN, 2004).
Neste contexto a fim de reforçar a importância deste profissional neste espaço, tramita no Brasil um projeto de lei que busca incluir o profissional enfermeiro nas creches e pré-escolas. Conforme o projeto de lei 1616/11 o enfermeiro deverá atuar em turno integral para cada rede pública de creches e escolas de educação infantil, realizando atendimento de emergência e fornecendo orientações aos professores, demais servidores e pais quanto às noções de atendimento de primeiros socorros.

Diante do contexto apresentado, o presente trabalho teve como objetivo conhecer a percepção dos enfermeiros, professores e supervisores pedagógicos quanto a inclusão do profissional enfermeiro em quatro instituições de educação infantil em Porto Alegre sendo duas privadas e duas municipais.

\section{PERCURSO METODOLÓGICO}

A pesquisa é de caráter qualitativo exploratória de cunho descritivo. $O$ estudo foi desenvolvido nas escolas de educação infantil do Município de Porto Alegre onde decidiu-se por duas participações de cada esfera, duas privadas, e duas municipais. Estas escolas foram incluídas por conveniência, incluindo apenas as que tivessem um enfermeiro no quadro de profissionais da escola.

A pesquisa de campo foi realizada após a aprovação do Comitê de ética e pesquisa do IPA (CEP) sob número de parecer 920.009 e da Secretaria Municipal de Saúde de Porto Alegre sob número de parecer 1.017.037. Foram entrevistados 4 supervisores pedagógicos ( 1 por escola), 4 enfermeiros (1 por escola) e 20 professores (5 por escola) de educação infantil.

O critério de inclusão consistiu em profissionais enfermeiros, professores e supervisores pedagógicos de escolas de educação infantil municipais e privadas, que aceitaram fazer parte da pesquisa e assinaram o Termo de Consentimento Livre Esclarecido (TCLE). Foram excluídas da pesquisa os profissionais que não atuem na educação infantil, que não aceitaram fazer parte da pesquisa, ou não concordaram em assinar o TCLE. Após aprovação dos CEP iniciou-se a coleta de dados através de entrevistas semi estruturadas com perguntas abertas para os entrevistados. O tempo médio de duração das entrevistas foi 
de 10 minutos para cada profissional. De maneira a obter informações fidedignas para o estudo, as entrevistas foram transcritas na íntegra. As Escolas, participantes da pesquisa tiveram o anonimato garantido, sendo, portanto, identificadas com a Letra E (de escola) seguidos da letra P (particular) e M (municipal). Os Profissionais Enfermeiros foram identificados com a palavra abreviada Enf. Os Supervisores pedagógicos com a palavra abreviada Sup. E, os professores com a palavra abreviada Prof.

Após a coleta dos dados, a análise foi realizada através da transcrição das gravações e foi utilizado o método de análise temática que, segundo Minayo (2004), é a forma de se agrupar as entrevistas em categorias temáticas conforme a frequência com que são citadas, de acordo com o objetivo analítico da pesquisa.

De acordo com Minayo (2004), as categorias são empregadas para se estabelecer classificações, ou seja, significa agrupar elementos, ideias ou expressões em torno de um conceito capaz de abranger tudo isso. Pode ser utilizado em qualquer tipo de análise em pesquisa qualitativa.

Para se realizar a análise temática, foi preciso desdobrá-la em três etapas: a pré-análise; exploração do material; tratamento dos resultados obtidos e interpretação. A fase de pré-análise é a etapa em que se selecionam as entrevistas a serem analisadas; retoma-se as hipóteses e objetivos, reformulando-os frente ao conteúdo obtido na pesquisa; e então elabora-se indicadores que orientem a interpretação final (MINAYO, 2008).

Já a fase de exploração do material é a parte em que se codifica o material obtido, quantificando unidades escolhidas a serem analisadas, como uma palavra, frase, personagem, tema, etc. E por último vem o tratamento dos resultados e interpretação, em que normalmente se transforma os resultados brutos obtidos em estatísticas simples ou complexas. É aí que o pesquisador faz interpretações previstas na sua base teórica ou criam-se novas pistas ao redor de campos teóricos sugeridos na leitura do material (MINAYO, 2008).

As gravações e as transcrições com as entrevistas ficarão armazenadas com a pesquisadora por um período mínimo de 5 anos e, após, destruídas de acordo com a Lei de Direitos Autorais 9.610/98 (BRASIL, 1998).

As categorias de análise foram definidas mediante o agrupamento das unidades de registro e com texto com características em comum ou que se relacionavam entre si.

\section{RESULTADOS E DISCUSSÃO}

Após a transcrição, houve a releitura dos discursos dos participantes da pesquisa o qual emergiram três categorias de análise: O enfermeiro nas escolas; Desafios da inclusão do enfermeiro nas escolas; Ações educativas em saúde, descritas e discutidas a seguir:

\section{O ENFERMEIRO NAS ESCOLAS}

As escolas de educação infantil, ou também chamadas de pré-escola são ambientes institucionais que recebem crianças antes da entrada no ensino obrigatório. Nesses locais as crianças são estimuladas através de atividades lúdicas a desenvolver suas habilidades motoras e cognitivas, fazer descobertas e iniciar a alfabetização (BRASIL, 2006a).

A forma de ver as crianças foi, ao longo do tempo, se modificando e atualmente olhamos para essa criança com um novo olhar contribuindo para que fosse reajustada uma nova função para as ações desenvolvidas com as crianças nas escolas envolvendo dois aspectos indissociáveis: educar e cuidar (BRASIL, 2006b).

A enfermagem é uma profissão da área da saúde, a qual tem como essência o cuidado ao ser humano, individual, na família ou na comunidade (SALAZAR, 2011). No referido trabalho esse cuidado refere-se ao ambiente escolar onde o enfermeiro realiza a assistência à saúde das crianças em idade escolar de diversas formas, como: consulta de enfermagem, aplicação de medicações e/ou vacinas, realização de curativos, desenvolve ações preventivas individuais ou coletivas. Em relação a essa temática alguns enfermeiros entrevistados reforçam esses aspectos por meio de suas falas:

Aqui na escola eu é que realizo o primeiro atendimento na sala da enfermaria quando uma criança se machuca. Eu avalio, medico conforme prescrição 
médica, observo a evolução do quadro e também comunico os pais. Caso seja algo mais grave ligo para o SOS que tem convênio com a escola. (E; P; Enf).

Na educação infantil realizo ações de prevenção de acidentes, hábitos de higiene, primeiros socorros, enfim, são muitas abordagens dentro de uma escola. E dependendo do caso, quando mais sério encaminho para uma avaliação médica à unidade de atendimento que fica aqui próximo no posto de saúde.(E; M; Enf.).

Eu faço a avaliação inicial e se necessário encaminho à unidade Básica. Aqui faço também a avaliação dos alunos quanto ao calendário vacinal, as imunizações. (E; M; Enf.).

No momento em que se discute a ideia de colocar um filho na escola, de imediato começa a preocupação em procurar aquela escola que atenderá as necessidades da família e que esteja capacitada a receber a criança para desenvolver nela suas potencialidades e habilidades através do processo ensino aprendizagem (ACIOLI, 2008).

A inserção do profissional enfermeiro capacitado nas escolas faz a diferença na qualidade prestada por essas unidades, pois entre outras atribuições, auxilia na troca de experiências junto aos pais nos cuidados de saúde com a população infantil dando continuidade ao trabalho realizado em casa. Um enfermeiro capacitado detém uma sólida base de conhecimentos e com isso faz a diferença, ao realizar uma assistência ao aluno de forma integral (RICCI, 2008).

Como profissionais da saúde, o enfermeiro não deve considerar somente o fisiológico do aluno naquele momento da procura pelo atendimento de enfermagem na escola, pois muito do seu comportamento pode estar relacionado ao que ele sente, pensa e fala (SILVA, 2011). As atividades a serem desenvolvidas também perpassam pela prevenção, conforme mencionado na fala abaixo:

Aqui realizo várias atividades de orientações para prevenir acidentes, realizo curativos quando necessário. Realizo atendimento de primeiros socorros registrando informações da criança e do atendimento e comunico os pais e, em casos mais graves chamo a Unimed. Quem me respalda é uma enfermeira porque eu sou acadêmica. Ela responde por mim. (E; P; Enf.).

No que se refere se os entrevistados possuem conhecimento sobre o Projeto de Lei 1616/11 que propõe a inserção do profissional de enfermagem em tempo integral nas escolas de educação infantil, apenas três supervisores e duas professoras relatam conhecer ou ouvir falar como descrito nas falas abaixo:

Já ouvi falar, mas não li. (E; P; Prof.).

Já tive contato, mas como essa é a nossa realidade,fiquei tranquila e satisfeita com tal projeto em função das escolas que não possuem esse profissional. (E; P; Sup.).

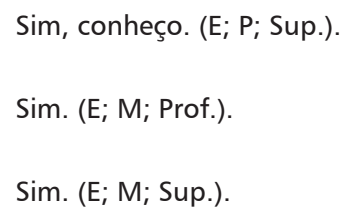

Diante do exposto fica evidente que o profissional enfermeiro tem uma atuação muito importante no espaço escolar e mostra-se disponível e muitas vezes resolutivo ao exercer o ato do cuidado oferecendo ajuda e apoio no momento que acolhe o aluno/criança de forma humanizada, contribuindo e participando do planejamento das ações de cuidado, uma vez, que observa e avalia diariamente aquele aluno (SALAZAR, 2011).

\section{DESAFIOS DA INCLUSÃO DO ENFERMEIRO NAS ESCOLAS}

Os cursos de graduação do profissional enfermeiro capacitam os egressos para promoção, proteção, manutenção e recuperação da saúde seja ela individual ou coletiva. O enfermeiro é qualificado para tal atuação possuindo embasamento técnico-científico para desenvolver suas atividades (COFEN, 2004).

A inclusão desse profissional seria para atuar como educador para a saúde, ensinar o indivíduo quanto ao autocuidado e junto com a equipe multiprofissional prestar um atendimento com enfoque preventivo. 
Os entrevistados da pesquisa quando questionados sobre a atuação do enfermeiro dentro das escolas são unânimes em referir que é muito importante e fundamental para esclarecimentos de várias dúvidas tanto deles enquanto trabalhadores com essa faixa etária como dos pais que muitas vezes procuram por informações mais específicas da área da saúde.

Estes fatos puderam ser observados nas descrições das entrevistas abaixo:

É fundamental pois as crianças precisam ter assistência de um profissional especializado na área. (E; P; Prof.).

Muito importante para prestar um primeiro atendimento rápido e de qualidade para que o aluno e a família sintam-se seguros e amparados. (E; P; Enf.).

Muito importante pois ajudaria até mesmo no auxilio aos pais e professores. (E; M; Prof.).

Acredito que seja de extrema importância pois não temos respostas para tudo, com o auxilio de um profissional teremos uma grande ajuda para resolver os casos até com esclarecimentos aos pais. (E;

A segurança referida nas falas por ter como integrante da equipe alguém habilitado e qualificado para o primeiro atendimento deixa os professores e demais integrantes da escola seguros e mais confiantes para transmitirem as informações aos pais e/ou cuidadores, demonstrando um diferencial na assistência.

As falas dos participantes da pesquisa refletem esta questão:

É de muita importância, nos sentimos mais seguros. (E; M; Sup.).

Daria as orientações certas para nós professores também porque as vezes temos muitas dúvidas. ( $\mathrm{E}$; M; Prof.).

O papel do enfermeiro é indispensável, não apenas como um profissional apto a atender situações de acidentes ou de mal estar, mas como um profissional que atua na promoção de saúde, podendo atuar junto aos professores e estudantes neste sentido, pensando e promovendo ações promotoras de bem estar. (E; P; Prof.).

Mesmo com todos esses benefícios positivos defendidos e descritos pelos entrevistados dessa pesquisa, sabemos que a inclusão desse profissional dentro das escolas ainda é discreto. Ao questionar os participantes se existe algum fator que dificulte as atividades do enfermeiro nas escolas, a maioria responde não haver dificuldades, porém, outros descrevem o que acham que dificultaria, como descrito abaixo:

Demanda de atendimento da escola, falta de entendimento da importância de um primeiro atendimento qualificado. (E; P; Prof.).

Poderíamos ter um profissional com carga horária prevista para essas ações de bem estar. (E; P; Prof.).

Sim. Falta de material como oxímetro, desfibrilador [...] a sala também deveria ser mais ampla. Pouco profissional para atender a demanda de alunos. (E; P; Enf.).

A quantidade de atendimento, muita demanda para pouco funcionário. (E; $P$; Sup.).

Sim, muitas como demanda do serviço, falta de estrutura, falta de material e de recursos humanos. Dificuldade em conciliar os horários da unidade com as creches e falta de interesse por parte de algumas delas. (Enf. Esc. Munic.).

Demanda muito grande de acidentes leves para apenas um enfermeiro. (E; P; Prof).

Penso que em primeiro lugar há o custo, depois pouca formação do profissional que exerce a função. (E; P; Prof).

Quanto às respostas dos entrevistados, houve semelhança entre a rede pública e a privada, o que mostra que estão em concordância com algumas dificuldades que o serviço aponta para o desenvolvimento das ações de enfermagem. Nas dificuldades apontadas não houve diferença mostrando que a escola particular apesar de ter um maior aporte financeiro o que permite mais investimentos em relação à infra-estrutura e contratação de mais profissional enfermeiro, não o faz de forma mais eficaz que a pública. 
Ao ensinar, dentro das escolas, noções básicas de cuidados com a saúde o enfermeiro reforça suas habilidades como educador, e ao compartilhar informações sobre promoção e prevenção com os demais trabalhadores da educação infantil reforça a importância de saberem o manejo adequado para o enfrentamento das vulnerabilidades que comprometem o pleno desenvolvimento das crianças (BRASIL, 2010).

A inclusão do profissional enfermeiro nas escolas de educação infantil proporcionará muitos benefícios às crianças, famílias e equipe multiprofissional que ali atuam.

\section{AÇÕES EDUCATIVAS EM SAÚDE}

O conceito tradicional de educação em saúde caracteriza-se pela identificação dos profissionais da saúde como legítimos executadores de ações voltadas para essa área. Em referenciais mais ampliados sobre o tema promoção da saúde sugere usar o termo ações educativas em saúde que levam em consideração a complexidade desta palavra. Essas ações estão voltadas para a promoção e proteção da saúde dos indivíduos, famílias e comunidade (BUSS, 2003).

O enfermeiro não está inserido nas instituições somente para transmitir informações ou realizar treinamentos, mas sim para mobilizar e sensibilizar as famílias e demais profissionais atuantes no ambiente escolar quanto às práticas da diversificação da arte do cuidado, pois educar ou educação em saúde não é somente transmissão de conhecimentos, é um processo de reflexão e aprendizagem. A prática educativa deverá ser reflexiva e acontecer sempre em conjunto coma as ações realizadas no cotidiano escolar (ACIOLI, 2008).

Essa categoria profissional desenvolve uma atribuição importante no ambiente escolar por ser uma profissão que desenvolve suas atividades de orientações buscando a promoção e prevenção das enfermidades. Nesse sentido o enfermeiro tem se constituído como um importante agente de ações educativas em saúde em vários espaços institucionais, um deles as escolas de educação infantil.

Quando perguntado às participantes da pesquisa quais as ações que o enfermeiro exerce na escola, elas são unanimes em relatar que são ações voltadas à promoção da saúde, prevenção de doenças e de acidentes na faixa etária escolar e estendem essas orientações aos demais profissionais que ali trabalham.

\begin{abstract}
Aqui na escola acontece muitas quedas, cortes na boca, crises de asma. Com orientações e apoio do enfermeiro poderíamos conduzir melhor determinadas situações. (E; M; Prof.).
\end{abstract}

\begin{abstract}
Na escola não tem nenhum treinamento de primeiros socorros, eu fiz quando saí do magistério a tempos atrás. Minha experiência é a de mãe, então se o enfermeiro pudesse realizar esse treinamento seria muito importante. (E; P; Prof.).
\end{abstract} Na escola realizo atividades quanto a prevenção de
acidentes, hábitos de higiene, cuidados com a saú-
de dos adolescentes. (E; M; Enf.).

Realizo atendimento de primeiros socorros, orientações quanto a higiene, quanto a curativos a ser utilizados e o porquê, enfim vou analisando a demanda do dia e tentando suprir. (E; P; Enf.).

As escolas de educação infantil caracterizam-se por serem locais onde o profissional enfermeiro pode desenvolver ações educativas de promoção, prevenção, manutenção e restauração da saúde, além de fornecer aos pais esclarecimentos e instruções apropriadas de situações que levem ao agravo de doenças na faixa etária infantil (KYLE, 2011).

O Programa Saúde na Escola (PSE) é uma política intersetorial da saúde e da educação que foi instituída em 2007voltada a atender crianças, adolescentes, jovens e adultos da educação pública brasileira que se unem para promover saúde e educação integral. O PSE é uma estratégia da escola e da Rede Básica de Saúde com a finalidade de proporcionar qualidade de vida da população com ações educativas em saúde (BRASIL, 2011).

Outra forma muito utilizada nas escolas voltada a ações educativas é a inserção por tempo determinado na forma de estágios de acadêmicos da graduação da área da saúde em parceria com as instituições levando informações e conhecimentos sob a forma de palestras e minicursos sobre o tema cuidados com a saúde (BRASIL, 2011). 
Dentro das práticas exercidas pela enfermeira, podemos ressaltar a atuação do profissional como educador contínuo nas ações de saúde, com conhecimento e capacidade para intervir nos problemas que possa acometer as crianças e suas famílias durante a primeira infância.

\section{REFERÊNCIAS}

ACIOLI, Sônia. A Prática educativa como expressão do cuidado em saúde pública. Revista Brasileira de Enfermagem, [S.I.], v. 61, n. 1, p. 117-121, 2008.

. Lei n. 7.498, de 25 de junho de 1986a. Regulamenta o Exercicio de Enfermagem). Diário Oficial [da] União. Brasília, DF, 25 jun. 1986a. Disponivel em: < http://www. planalto.gov.br/ccivil_03/leis/17498.htm >. Acesso em: 13 maio 2015.

Lei n. 9.394, de 20 de dezembro de 1996. Lei de Diretrizes e Bases da Educação. Diário Oficial [da] União. Brasília, DF, 20 dez. 1996. Disponível em: <http://portal.mec. gov.br/arquivos/pdf/ldb.pdf>. Acesso em: 27 mar. 214.

- Manual de prevenção de acidentes e primeiros socorros nas escolas/Secretária da Saúde. Coordenação de Desenvolvimento de Programas e Políticas de Saúde. CODEPPS. São Paulo: SMS,2007. 129p.

- Ministério da Educação. Funcionários de escola: cidadãos, educadores, profissionais e gestores. 2. ed. Brasília: Ministério da Educação, 2006b.

- Ministério da Educação. Política Nacional de Educação Infantil: pelo direito das crianças de zero a seis anos à educação. Brasília: Ministério da Educação, 2006a.

. Ministério da Saúde. Ações de promoção da saúde e prevenção de doenças e agravos. Brasília: Ministério da Saúde, 2010.
. Ministério da Saúde. Passo a passo PSE: Programa Saúde na Escola: tecendo caminhos da intersetorialidade. Brasília: Ministério da Saúde, 2011.

. Ministério da Saúde. Saúde Brasil 2010: uma análise da situação de saúde e de evidências selecionadas de impacto de ações de vigilância em saúde. Brasilia: Ministério da Saúde, 2011.

Referencial curricular nacional para educação infantil. Brasília: MEC/SEF, 1998.

BUSS PM. Uma introdução ao conceito de promoção da saúde. In: Czeresnia D, Freitas CM, organizadores. Promoção da saúde: conceitos, reflexões, tendencias. Rio de Janeiro: Fiocruz, 2003. P. 15-38.

COFEN. Código de ética e legislação: Lei n 7.498/86 regulamentado pelo Decreto 94.406/87. Rio de Janeiro: COFEN, 2004.

KYLE, T. Enfermagem pediátrica. Rio de Janeiro: Guanabara Koogan, 2011.

MINAYO, M.C.S. O Desafio do conhecimento: pesquisa qualitativa em saúde. 8. ed. São Paulo: Hucitec, 2004.

O Desafio do conhecimento: pesquisa qualitativa em saúde. 11. ed. São Paulo: Hucitec, 2008.

RICCI, S.S. Enfermagem materno-neonatal e saúde da mulher. Rio de Janeiro: Guanabara Koogan, 2008.

SALAZAR, O.A.B. Rejeição dos pacientes no cuidado do enfermeiro. Invest. Educ. Enferm., [S.I.], v. 29, n. 3, p. 343352, 2011.

SILVA, M.J.P. Comunicação tem remédio: a comunicação nas relações interpessoais em saúde. 8. ed. São Paulo: Loyola, 2011. 